\title{
Hubungan Higiene Sanitasi Terhadap Telur Nematoda Usus Pada Lalapan Mentah di Warung Pecel Lele Sepanjang Jalan Z.A Pagar Alam Bandar Lampung
}

\author{
Sri Wantini, Eka Sulistianingsih \\ Jurusan Analis Kesehatan Politeknik Kesehatan Tanjungkarang
}

\begin{abstract}
Abstrak
Kebiasaan mengkonsumsi sayuran mentah perlu hati-hati terutama jika dalam pencucian kurang baik sehingga kemungkinan masih terdapat telur cacing pada sayuran tersebut. Pada umumnya pedagang kaki lima menjual menu andalannya dengan cara membuka tempat yang tidak permanen di pinggir jalan, sehingga kebersihan tempat perlu dijaga. Cara penularan telur cacing Soil Transmitted Helmints ke manusia dapat dikarenakan memakan sayuran yang kurang matang, dan tidak dicuci dengan bersih menggunakan air mengalir secara langsung, serta meminum air yang terkontaminasi telurcacing. Hampir seluruh penduduk Indonesia mengkonsumsi sayuran. Jenis penelitian kuantitatif desain penelitian cross sectional dengan Uji Chi Square, untuk mengetahui hubungan higiene sanitasi terhadap telur cacing nematoda usus pada lalapan mentah di warung sepanjang jalan Z.A.Pagar Alan Bandar lampung. Hasil Penelitian univariat dari 12 warung yang memiliki higiene sanitasi baik sebanyak $5(41,7 \%)$ dan yang memiliki higiene sanitasi buruk sebanyak 7 (58,3\%). Pada sampel kemangi ditemukan telur Ascaris lumbricoides sebanyak 1 ( 8,3\%) sedangkan paada kubis ditemukan telur Ascaris lumbricoides sebanyak 4(33,3\%) dan telur Trichuris trichiura sebanyak 1 (8,3\%). Hasil penelitian bivariat didapatkan nilai $p$ value $0,014<a 0,05$ yang artinya ada hubungan higiene sanitasi terhadap telur nematoda usus pada lalapan mentah di warung pecel lele sepanjang jalan Z.A. Pagar Alam Bandar Lampung.
\end{abstract}

Kata Kunci: Higiene sanitasi, Telur cacing Nematoda usus, dan Lalapan mentah

\section{Relationship Between Sanitary Hygiene of Intestinal Nematode Eggs on Raw Vegetables at Warung Pecel Lele on the street Z.A Pagar Alam Bandar Lampung}

\begin{abstract}
The habit of consuming raw vegetables needs to be careful especially if the washing is not good so the possibility of worm eggs in the vegetables is still possible. In general, street vendors sell their flagship menu by opening a place that is not permanent on the side of the road, so that the cleanliness of the place needs to be maintained. How to transmit eggs to Soil Transmitted Helmints worms to humans can be caused by eating undercooked vegetables, and not being washed clean using direct flowing water, and drinking water contaminated with eggworms. Almost all Indonesian people consume vegetables. This type of research is quantitative cross-sectional research design with Chi Square Test, to determine the relationship of sanitary hygiene to intestinal nematode worm eggs in raw vegetables in stalls along the road Z.A. Fence Alan Bandar Lampung. Univariate research results from 12 stalls that had good sanitation hygiene as many as $5(41.7 \%)$ and those with poor sanitation hygiene as much as 7 (58.3\%). In basil samples, there were 1 (8.3\%) Ascaris lumbricoides eggs while Ascaris lumbricoides eggs as much as $4(33.3 \%)$ and Trichuris trichiura eggs as much as $1(8.3 \%)$. The results of bivariate research obtained $p$ value $0.014<\alpha 0.05$, which means that there is a relationship between sanitation hygiene of intestinal nematode eggs in raw vegetables in catfish pecel stalls on the street Z.A. Pagar Alam Bandar Lampung.
\end{abstract}

Keywords: Sanitary hygiene, intestinal Nematode worm eggs, and raw Vegetables

Korespondensi: Sri Wantini, Jurusan Analis Kesehatan Politeknik Kesehatan Tanjungkarang, Jalan SoekarnoHatta No. 1 Bandar Lampung, mobile phone: 082183416882, e-mail: sriwantini@ poltekkes-tjk.ac.id 


\section{Pendahuluan}

Kecacingan adalah masalah kesehatan yang masih banyak ditemukan. Berdasarkan data dari World Health Organization (WHO)tahun 2014, lebih dari 1,5 miliar orang atau $24 \%$ dari populasi dunia terinfeksi Soil Transmitted Helminths (STH).

World Health Organization (WHO) mengklasifikasikan infeksi cacing yang ditularkan melalui tanah (Soil Transmitted Helminths) ke dalam salah satu penyakit yang diabaikan (Neglected Tropical Diseases) karena merupakan infeksi yang paling umum terjadi di seluruh dunia. Penularan cacing ini melalui telur yang ada dalam kotoran manusia yang dapat mencemari tanah di daerah yang sanitasinya buruk, dan di daerah yang beriklim tropis dan subtropis. (World Health Organization, 2015).

Indonesia merupakan negara yang beriklim tropis. Prevalensi kecacingan di Indonesia mencapai76,67\%. Prevalensidi Sumatera mencapai78\%, Kalimantan 79\%, Sulawesi $88 \%$, NusaTenggara Barat 92\% dan Jawa barat 90\%.( Inge, Ismid, Syarifudin, \& Saleha, 2015). Nematoda usus yang masih menjadi masalah kesehatan masyarakat Indonesia yaitu cacing gelang (Ascarislumbricoides), cacing cambuk (Trichuris trichiura) dan cacingtambang (Ancylostoma duodenale dan Necator americanus).

Cara penularan telur cacing Soil Transmitted Helmints ke manusia dapat dikarenakan memakan sayuran yang kurang matang, dan tidak dicuci dengan bersih menggunakan air mengalir secara langsung, serta meminum air yang terkontaminasi telurcacing. Hampir seluruh penduduk Indonesia mengkonsumsi sayuran (Badan Pusat Statistik, 2017)

Kebiasaan mengkonsumsi sayuran mentah perlu hati-hati terutama jika dalam pencucian kurang baik sehingga kemungkinan masih terdapat telur cacing pada sayuran tersebut. Kebiasaan makan sayuran mentah ini, sudah menjadi kebiasaan masyarakat di Indonesia sehingga kelihatannya sulit diubah. Masyarakat juga mempunyai kebiasaan memakan sayuran dalam bentuk lalapan untuk campuran makanan lain. Lalapan sangat baik untuk pencernaan karena mengandung banyak serat yang juga merupakan makanan pendamping dari menu pecel (ayam, lele atau tahu tempe goreng) dengan sambal (id.wikipedia.org, 10/6/2018).
Menu pecel banyak digemari oleh masyarakat karena cukup bergizi, enak, murah, dan cepat saji. Pengolahan yang mudah dan penyajian yang cepat, sehingga menu tersebut dapat ditemukan pada pedagang kaki lima. Pada umumnya pedagang kaki lima menjual menu andalannya dengan cara membuka tempat yang tidak permanen di pinggir jalan, sehingga kebersihan tempat perlu dijaga (Agustin, T.E.; Adriyani, R., 2008: 70).

Bedasarkan penelitian yang pernah dilakukan di pasar tradisional dan pasar modern Kota Bandar Lampung, ditemukan angka kontaminasi Soil Transmitted Helminths (STH) pada sayuran kubis dan selada yang cukup tinggi. Angka kontaminasi telur Soil Transmitted Helminths (STH) di pasar tradisional yaitu sebesar $76,1 \%$ dengan proporsi telur Ascaris lumbricoides 43,2\%, Trichuristrichiura 10,2\% dan keduanya 22,7\%. Pada pasar modern angka kontaminasi telur cacing sebesar 58,3\% dengan proporsi telur Ascaris lumbricoides 16,6\%, Trichuris trichiura 19,7\% dan keduanya 21,8\% (Almi, 2011; Indriani, 2011).

Dari hasil penelitian telur nematoda usus pada lalapan kubis oleh Wardhana KP, dkk (2014) di warung-warung makan Universitas Lampung dengan jumlah 42 sampel penelitian, didapatkan 11 sampel $(26,19 \%)$ terkontaminasi oleh telur nematoda usus. Jenis telur cacing yang ditemukanadalah telur Ascaris lumbricoides sebanyak 6 sampel (14,28\%), telur Trichuris trichiurasebanyak 3 sampel $(7,14 \%)$, dan 2 sampel $(4,76 \%)$ lalapan kubis terkontaminasi kedua jenis telur cacing ini.

Jalan ZA Pagar Alam merupakan salah satu daerah pusat kuliner dan lingkungan pendidikan di Bandar Lampung, sehingga daerah tersebut tidak pernah sepi dari aktivitas masyarakat Lampung dan sekitarnya. Sebagian besar warganya adalah para pedagang sehingga banyak peluang usaha, salah satunya berdagang pecel lele. Ramainya aktivitas masyarakat yang tiada henti di jalan ZA Pagar Alam dikhawatirkan menjadi penyebab pedagang pecel lele di sepanjang jalan kurang memperhatikan kebersihan dagangannya. Dari survei yang telah dilakukan terhadap pedagang pecel lele di jalan ZA Pagar Alam, didapatkan kondisi trotoar yang tingginya hampir sejajar dengan jalan dan hamper seluruh pedangan tidak mempunyai sumber air bersih dan mengalir. Bila dalam proses pencucian sayuran tidak baik, telur cacing kemungkinan masih melekat pada sayuran dan tertelan saat sayuran 
dikonsumsi (Widjaja, junus dkk. 2014; Vol. 5 No.2)

Tujuan penelitian ini untuk mengetahui hubungan higiene sanitasi terhadap telur nematoda usus pada lalapan mentah di warung pecel lele di sepanjang jalan ZA Pagar Alam Bandar Lampung.

\section{Metode}

Jenis penelitian yang digunakan adalah deskriftif dengan menggunakan rancangan cross sectional. Populasi pada penelitian ini adalah seluruh warung pecel lele sepanjang Jalan ZA Abidin Pagar Alam Bandar Lampung sebanyak 12 pedagang yang mendirikan warung di atas trotoar / tidak permanen. Sampel dalam penelitian ini adalah total populasi yang diambil dari setiap pedagang pecel lele dengan menggunakan teknik pengambilan sample yaitu total sampling. Pemeriksaan telur cacing nematoda usus pada lalapan mentah (daun kemangi dan kubis) dilakukan di laboratorium Parasitologi Jurusan Analis Kesehatan Poltekkes Tanjungkarang. Penelitian dilakukan pada bulan Desember 2018.

Untuk mengetahui higiene sanitasi warung pecel lele, maka dilakukan pengisian kuisoner yang berisi tentang sanitasi tempat jual, sumber air, cara mencuci lalapan, dan cara penyajian lalapan. Analisis data bivariat dalam penelitian ini menggunakan uji chi square test, untuk mengetahui hubungan higiene sanitasi terhadap telur nematoda usus pada lalapan mentah

\section{Hasil}

Jumlah sampel dalam penelitian ini sebanyak 12 sampel. Hasil kuesioner tentang higiene sanitasi warung pecel lele di sepanjang jalan ZA Pagar Alam Bandar Lampung sebagai berikut:

Tabel 1. Distribusi frekuensi higiene sanitasi warung pecel lele di sepanjang jalan Z.A Pagar Alam Bandar Lampung

\begin{tabular}{cccc}
\hline No & Kategori & jumlah & $\%$ \\
\hline 1. & Higiene sanitasi baik & 5 & 41.7 \\
2. & Higiene sanitasi buruk & 7 & 58.3 \\
& Total & 12 & 100 \\
\hline
\end{tabular}

Berdasarkan tabel 1. hasil kuesioner yang diberikan kepada 12 pedagang didapatkan warung pecel lele dengan sanitasi baik yaitu sebanyak 5 warung $(41.7 \%)$ dan didapatkan warung pecel lele dengan sanitasi buruk sebanyak 7 warung (58.3\%).

Persentase telur nematoda usus (Ascaris lumbricoides dan Trichuris trichiura) pada lalapan mentah (daun kemangi dan kubis ) di warung pecel lele sepanjang jalan Z.A Pagar Alam Bandar Lampung, sebagai berikut:

Tabel 2. Distribusi frekuensi telur Nematoda usus pada lalapan mentah warung di sepanjang jalan Z.A Pagar Alam Bandar Lampung 2018.

\begin{tabular}{cccccccc}
\hline \multirow{2}{*}{$\begin{array}{c}\text { Jenis } \\
\text { lalapan }\end{array}$} & $\begin{array}{c}\text { Ascaris } \\
\text { lumbricoides }\end{array}$ & $\%$ & $\begin{array}{c}\text { Trichuris } \\
\text { trichiura }\end{array}$ & $\%$ & Tidak ada & $\%$ & \multirow{2}{*}{ Jumlah } \\
\cline { 2 - 7 } Kemangi & 1 & 8,3 & 0 & 0 & 11 & 91,7 & 12 \\
Kubis & 4 & 33,3 & 1 & 8,3 & 7 & 58,3 & 12 \\
\hline
\end{tabular}

Dari tabel 2 menunjukkan hasil penelitian menunjukkan jumlah telur nematoda usus pada lalapan mentah kemangi didapatkan telur cacing Ascaris lumbricoides sebanyak 1 sampel (8.3\%), dan sebanyak 11 sampel $(91.7 \%)$ tidak didapatkan telur cacing telur nematoda usus. Dan jumlah telur nematoda usus pada lalapan mentah kubis di dapatkan telur cacing Ascaris lumbricoides sebanyak 4 sampel (33.3\%\%), didapatkan telur cacing Trichuris trichiura sebanyak 1 sampel $(8.3 \% \%)$ dan sebanyak 7 sampel (58.3\%) tidak didapatkan telur cacing telur nematoda usus.
Analisa bivariat dilakukan dengan menggunakan uji Chi Square untuk melihat adanya hubungan higiene sanitasi terhadap telur cacing nematoda usus pada lalapan mentah di warung pecel lele sepanjang jalan ZA Pagar Alam. Diperoleh nilai $p$ value sebesar 0,014 lebih kecil dari nilai 0,05 artinya didapatkan ada hubungan higiene sanitasi terhadap telur cacing nematoda usus pada lalapan mentah di warung pecel lele sepanjang jalan ZA Pagar Alam, seperti yang dapat dilihat pada tabel dibawah ini. 
Tabel 3. Hubungan higiene sanitasi terhadap telur Nematoda usus pada lalapan kemangi mentah warung di sepanjang jalan Z.A Pagar Alam Bandar Lampung

\begin{tabular}{cccccc}
\hline Higiene & \multicolumn{3}{c}{ Telur Nematoda Usus } & Jumlah & p value \\
\cline { 2 - 4 } Sanitasi & Tidak ada & Tidak ada & Tidak ada & & \\
\cline { 2 - 4 } Baik & 5 & 0 & 0 & 5 & 0,014 \\
Buruk & 1 & 5 & 1 & 7 & \\
Total & 6 & 5 & 1 & 12 & \\
\hline
\end{tabular}

Dari tabel 3. menunjukkan nilai $p$ value sebesar $0.014(\alpha=0.05)$, hal ini menunjukkan bahwa ada hubungan higiene sanitasi terhadap telur cacing nematoda usus pada lalapan mentah di warung pecel lele sepanjang jalan Z.A Pagar Alam.

\section{Pembahasan}

Hasil pengumpulan data higiene sanitasi di warung pecel lele di sepanjang jalan Z.A Pagar Alam Bandar Lampung dari kuesioner yang diberikan kepada 12 pedagang telah dikategorikan menjadi higiene sanitasi baik dan higiene sanitasi buruk didapatkan warung pecel lele dengan higiene sanitasi baik yaitu sebanyak 5 warung dan didapatkan warung pecel lele dengan higiene sanitasi buruk ada 7 warung. Warung pecel lele yang dikategorikan dengan higiene sanitasi buruk yaitu sebanyak 7 warung pecel lele dengan bangunan warung pecel lele tidak permanen, warung pecel lele berada di atas trotoar, tidak terdapat air mengalir di warung pecel lele, membeli lalapan mentah di pasar tradisional, lalapan dicuci di warung, lalapan tidak dicuci dengan air mengalir, lalapan saat dicuci tidak dibuka perhelai, lalapan disajikan terbuka. Sedangkan warung pecel lele yang dikategorikan dengan higiene sanitasi baik yaitu sebanyak 5 warung pecel lele yang walaupun bangunan warung pecel lele tidak permanen, dan warung pecel lele berada di atas trotoar, dan penjual membeli lalapan mentah di pasar tradisional, serta lalapan disajikan terbuka tetapi diantara 5 warung dengan sanitasi baik ada 2 warung pecel lele yang terdapat air mengalir di warung kemudian mencuci lalapan di warung menggunakan air mengalir dengan membuka lalapan perhelainya, dan ada 3 warung pecel lele dengan higiene sanitasi baik tersebut tidak memiliki air mengalir di warung tetapi mencuci lalapan di rumah dengan menggunakan air mengalir dan dicuci dengan membuka lalapan perhelainya.

Menurut Chandra (2006), higiene dan sanitasi makanan merupakan upaya-upaya yang ditujukan untuk kebersihan dan keamanan makanan agar tidak menimbulkan bahaya keracunan dan penyakit pada manusia. Sedangkan secara operasional bahwa higiene sanitasi merupakan upaya untuk mengendalikan faktor risiko terjadinya kontaminasi terhadap makanan, baik yang berasal dari bahan makanan, orang, tempat dan peralatan agar aman dikonsumsi. Higiene sanitasi yang diteliti oleh peneliti telah sesuai dengan konsep teori dan oprasional yang terdiri dari faktor risiko terjadinya kontaminasi terhadap makanan yaitu higiene sanitasi (cara mencuci lalapan) yang berpengaruh terhadap adanya telur nematoda usus pada lalapan mentah.

Secara konsep menurut Lestari (2015) banyak faktor yang mempengaruhi sayuran terkontaminasi telur nematoda usus, yaitu kebiasaan defekasi di tanah dan pemakaian tinja sebagai pupuk kebun (diberbagai daerah tertentu) berpengaruh dalam penyebaran infeksi. Pencegahan terjadinya kontaminasi sayuran dengan telur nematoda usus yaitu dengan memperhatikan cara mencuci sayuran sebelum sayuran disajikan sebagai lalapan (dimakan mentah). Berdasarkan hasil pemeriksaan telur nematoda usus pada lalapan mentah kemangi dan kubis di warung pecel lele sepanjang jalan Z.A Pagar Alam Bandar Lampung dari 12 sampel kemangi yang terdapat telur cacing Ascaris lumbricoides yaitu sebanyak 1 sampel $(8.3 \%)$ dan sebanyak 11 sampel (91.7\%) tidak ada telur nematoda usus. Dan pada hasil pemeriksaan telur nematoda usus pada lalapan mentah kubis di dapatkan telur cacing Ascaris lumbricoides yaitu sebanyak 4 sampel (33.3\%) dan di dapatkan telur cacing Trichuris trichiura sebanyak 1 sampel $(8.3 \%)$ dan sebanyak 7 sampel $(58,3 \%)$ tidak ada telur nematoda usus.

Berdasarkan data yang telah di kumpulkan dari kuesioner mengenai higiene sanitasi dan data hasil pemeriksaan telur nematoda usus pada lalapan kemangi dan kubis di warung pecel lele sepanjang jalan Z.A Pagar Alam Bandar Lampung, telah dilakukan uji analisa bivariat dengan menggunakan uji $C h i$ Square untuk melihat adakah hubungan higiene 
sanitasi terhadap telur cacing nematoda usus pada lalapan mentah di warung pecel lele sepanjang jalan ZA Pagar Alam. Diperoleh nilai $p$ value 0,014 yang lebih kecil dari nilai 0,05 artinya didapatkan ada hubungan yang bermakna antara higiene sanitasi terhadap telur cacing nematoda usus pada lalapan mentah di warung pecel lele sepanjang jalan ZA Pagar Alam Bandar Lampung 2018.

Penelitian ini sesuai konsep dari Lestari (2015) yang menjelaskan, cara mencuci sayuran merupakan hal yang perlu diperhatikan sebelum sayuran disajikan sebagai lalapan (dimakan mentah). Mencuci sayur dengan air yang mengalir akan membuat sayur menjadi bersih, karena air yang datang ke sayur dalam kondisi bersih akan membawa kotoran, debu, kuman, parasit (telur nematoda usus) dan lain sebagainya ke air buangan yang telah terlepas terbawa air dan juga dengan mencuci serta memisahkan sayuran tiap lembar dibersihkan semua kotoran yang melekat pada sayuran dengan air mengalir. Kebiasaan mencuci sayuran/ lalapan mentah dengan teknik merendam di dalam wadah seperti baskom atau tidak dicuci menggunakan air mengalir tidak disarankan karena kotoran atau telur cacing yang tadinya terlepas bisa menempel kembali di sayuran dan dapat meningkatkan kemungkinan terkena penyakit yang disebarkan oleh perantara-perantara makanan karena terjadinya kontaminasi mikroorganisme salah satunya telur nematoda usus terhadap sayuran/ lalapan yang di konsumsi secara mentah.

Penelitian ini sesuai dengan hasil penelitian Umi Alfiani, Sulistiyani, Praba Ginanjar (2018) yang berjudul Hubungan Higiene Personal Padagang dan Sanitasi Makanan dengan Keberadaan Telur Cacing Soil Transmitted Helminths (STH) pada Lalapan Penyetan Di Warung Pujasera Simpanglima Kota Semarang, bahwa higiene sanitasi (praktik mencuci lalapan)memiliki hubungan yang bermakna terhadap telur cacing Soil Transmitted Helminths (STH) pada Lalapan Penyetan Di Warung Pujasera SimpanglimaKota Semarang (2018). Hal serupa juga disebutkan pada hasil penelitian Wardhana KP， dkk (2014) bahwa proses pencucian merupakan salah satu faktor yang sangat mempengaruhi kontaminasi telur soil transmitted helminths pada lalapan kubis di warung-warung makan Universitas Lampung dengan jumlah 42 sampel penelitian, didapatkan 11 sampel $(26,19 \%)$ terkontaminasi oleh telur nematoda usus. Jenis telur cacing yang ditemukanadalah telur Ascaris lumbricoides sebanyak 6 sampel (14,28\%), telur Trichuris trichiurasebanyak 3 sampel (7,14\%), dan 2 sampel (4,76\%) lalapan kubis terkontaminasi kedua jenis telur cacing ini.

Higiene dan sanitasi mempunyai tujuan yang sama dan erat kaitannya antara satu dengan lainnya yaitu melindungi, memelihara, dan mempertinggi derajat kesehatan manusia (individu maupun masyarakat). Menurut Chandra (2006) dan Oginawati (2008), tujuan dari higiene sanitasi makanan antara lain yaitu; menjamin keamanan dan kebersihan makanan, mencegah penularan wabah penyakit, melindungi konsumen dari kemungkinan terkena penyakit yang disebarkan oleh perantara-perantara makanan. Oleh sebab itu higiene sanitasi tidak terlepas dari faktor faktor risiko terjadinya kontaminasi telur nematoda usus terhadap makanan lalapan mentah, yaitu; sayuran/ lalapan (bahan makanan) yang tidak dicuci dengan air mengalir oleh pedagang, tempat pedagang mencuci lalapan di warung (tempat) yang tidak ada sumber air mengalir dan pedagang yang memiliki warung pecel lele tidak permanen di atas trotoar akan berisiko membawa debu jalan yang terdapat telur nematoda usus menempel di makanan / lalapan mentah tersebut. Maka dari itu perlu adanya izin dinas pemerintah setempat (dinas perdagangan) agar mendapatkan pengawasan.

Penelitian ini dilakukan untuk mengetahui ada tidaknya hubungan higiene sanitasi terhadap telur cacing nematoda usus pada lalapan mentah di warung pecel lele sepanjang jalan Z.A Pagar Alam. Berdasarkan hasil uji statistik diperoleh nilai dari uji chi squaredengan nilai pvalue0,014 yang lebih kecil dari nilai 0,05 artinya didapatkan ada hubungan yang bermakna antara higiene sanitasi terhadap telur cacing nematoda usus pada lalapan mentah di warung pecel lele sepanjang jalan ZA Pagar Alam Bandar Lampung.

Simpulan dalam penelitian ini yaitu pada 12 warung pecel lele di sepanjang jalan Z.A Pagar Alam Bandar Lampung didapatkan warung pecel lele dengan higiene sanitasi baik yaitu sebanyak 5 warung (41.7\%) dan di dapatkan warung pecel lele dengan higiene sanitasi buruk ada 7 warung $(58.3 \%)$. Hasil pemeriksaan telur nematoda usus pada 12 sampel kemangi didapatkan telur cacing Ascaris lumbricoides yaitu sebanyak 1 sampel $(8.3 \%)$ dan sebanyak 11 sampel $(91.7 \%)$ tidak ada telur nematoda usus. Dan pada 12 sampel kubis didapatkan telur cacing Ascaris lumbricoides yaitu sebanyak 4 sampel (33.3\%) 
dan didapatkan telur cacing Trichuris trichiura sebanyak 1 sampel $(8.3 \%)$ dan sebanyak 7 sampel $(58,3 \%)$ tidak ada telur nematoda usus. Hasil uji chi square didapatkan nilai $p$ value 0.014 lebih kecil dari nilai 0.05 , hal ini menunjukkan adanya hubungan yang bermakna antara higiene sanitasi terhadap telur cacing nematoda usus pada lalapan mentah di warung pecel lele sepanjang jalan ZA Pagar Alam Bandar Lampung.

Saran yang dapat diberikan yaitu: bagi pedagang agar dapat meningkatkan kualitas lalapan yang disajikan dengan memperhatikan higiene sanitasi makanan khususnya sanitasi tempat jual, sumber air, cara mencuci lalapan, dan cara penyajian lalapan. Memiliki surat ijin berdagang sepanjang jalan Z.A Pagar Alam dari dinas perdagangan agar mendapat pengawasan. Selain itu disarankan agar dilakukan penelitian tentang hubungan higiene sanitasi terhadap mikroorganisme selain nematoda usus seperti protozoa usus atau bakteri pada lalapan mentah

\section{Daftar Pustaka}

Agustin, T.E., Adriyani, R., Higiene dan Sanitasi Nasi Tempe Penyet Pedagang Kaki Lima Jalan Karangmenjangan Surabaya, Jurnal Kesehatan Lingkungan Vol.4, No.2, 2008. 69-80 (https://www.researchgate.net.10/6/2018)

Alfiani, U., Sulistiyani., Ginandjar, P., Hubungan Higiene Personal Pedagang Dan Sanitasi Makanan Dengan Keberadaan Telur Cacing Soil
Transmitted Helminths (STH) Pada Lalapan Penyetan Di Pujasera Simpanglima Kota Semarang, Jurnal Kesehatan Masyarakat e-Journal Vol 6, No.1, Januari 2018, ISSN: 2356-3346) (http://ejournal3.undip.ac.id/index.php/jk m)

Almi DU, 2011. Identifikasi Soil Transmitted Helminths pada Sayuran Kubis dan Selada di PasarTradisional Kota Bandar Lampung. Universitas Lampung. Bandar Lampung. Hlm: 35-37.

Badan Pusat Statistik, 2017, Konsumsi Buah dan Sayur Susenas Maret 2016. Brooker et al; licensee BioMed Central Ltd. 2009

Chandra, Budiman. 2006. Pengantar Kesehatan Lingkungan.Jakarta: EGC (http://repository.usu.ac.id/bitstream/han dle/123456789/34589/Chapter\%20II.pdf? sequence $=4$ ) Diakses Pada 23 Januari 2019.

Lestari, Puji. 2015. Identifikasi Telur Nematoda Usus pada Lalapan yang dijual Pedagang Pecel Lele di Kelurahan Karang Sari Kota Tangerang.

Widjaja, junus dkk. 2014. Pravelensi dan Jenis telur cacing soil transmitted helmint eggs (STH) pada sayuran kemangi di pedagang ikan bakar di Kota Palu. Jurnal buski Balai LitbangP2B2 Donggala. Vol. 5 No.2.

World Health Organization. 2015

Wolipop. detik.com, 10/6/2018id.wikipedia.org, 10/6/18 